\title{
Article
}

\section{Clinical-Pathological and Molecular Evaluation of 451 NIFTP Patients from a Single Referral Center}

\author{
Paola Vignali ${ }^{1}$, Agnese Proietti ${ }^{1}$, Elisabetta Macerola ${ }^{1} \oplus$, Anello Marcello Poma ${ }^{1}$, Liborio Torregrossa ${ }^{1}(\mathbb{D}$, \\ Clara Ugolini ${ }^{1}$, Alessio Basolo ${ }^{2}{ }^{(\mathbb{D}}$, Antonio Matrone ${ }^{2}\left(\mathbb{D}\right.$, Teresa Rago ${ }^{2}$, Ferruccio Santini ${ }^{2}{ }^{(\mathbb{D}}$, Rossella Elisei ${ }^{2}{ }^{(\mathbb{D}}$, \\ Gabriele Materazzi ${ }^{1}$ and Fulvio Basolo ${ }^{1, *(1)}$
}

1 Department of Surgical, Medical, Molecular Pathology and Critical Area, University of Pisa, 56126 Pisa, Italy; paola.vignali@phd.unipi.it (P.V.); a.proietti@ao-pisa.toscana.it (A.P.); elisabetta.macerola@for.unipi.it (E.M.); marcello.poma@med.unipi.it (A.M.P.); l.torregrossa@ao-pisa.toscana.it (L.T.); clara.ugolini@unipi.it (C.U.); gabriele.materazzi@med.unipi.it (G.M.)

2 Department of Clinical and Experimental Medicine, University of Pisa, 56126 Pisa, Italy; alessio.basolo@med.unipi.it (A.B.); antonio.matrone@med.unipi.it (A.M.); rago@endoc.med.unipi.it (T.R.); ferruccio.santini@med.unipi.it (F.S.); rossella.elisei@med.unipi.it (R.E.)

* Correspondence: fulvio.basolo@med.unipi.it; Tel.: +39-050-99-2892; Fax: +39-050-99-2481

check for updates

Citation: Vignali, P.; Proietti, A.;

Macerola, E.; Poma, A.M.;

Torregrossa, L.; Ugolini, C.; Basolo,

A.; Matrone, A.; Rago, T.; Santini, F.;

et al. Clinical-Pathological and

Molecular Evaluation of 451 NIFTP

Patients from a Single Referral Center.

Cancers 2022, 14, 420. https://

doi.org/10.3390/cancers14020420

Academic Editor: Vasyl Vasko

Received: 16 December 2021

Accepted: 12 January 2022

Published: 14 January 2022

Publisher's Note: MDPI stays neutral with regard to jurisdictional claims in published maps and institutional affiliations.

Copyright: (c) 2022 by the authors. Licensee MDPI, Basel, Switzerland. This article is an open access article distributed under the terms and conditions of the Creative Commons Attribution (CC BY) license (https:// creativecommons.org/licenses/by/ $4.0 /)$.
Simple Summary: Non-invasive follicular thyroid neoplasms with papillary-like nuclear features (NIFTP) are follicular thyroid neoplasm with an indolent clinical behaviour. In this study, we evaluated a retrospective series of 451 NIFTPs, of which 197 (43.7\%) presented in coexistence with collateral thyroid tumours. Unifocal and multifocal NIFTPs did not show peculiar ultrasound, cytological, molecular, and histo-pathological characteristics. Considering the high rate of coexisting carcinomas, NIFTP patients might benefit from monitoring of the contralateral lobe.

\begin{abstract}
Background: Non-invasive follicular thyroid neoplasms with papillary-like nuclear features (NIFTPs) were introduced in thyroid pathology in 2016. NIFTPs are a group of follicular neoplasm with an indolent behaviour. In this study, we gathered a large retrospective cohort of NIFTPs and compared those presenting as solitary lesions and NIFTPs found in multifocal setting. Methods: A retrospective search of NIFTPs was performed, and the clinico-pathological features were recorded. For a subgroup of patients, pre-surgical ultrasound (US) evaluation, cytological diagnosis, and molecular analysis were available. Results: We collected 451 NIFTPs; 254 (56.3\%) were truly solitary tumours, while 197 coexisted with one or more NIFTP/cancer. Contrasting unifocal and multifocal settings, NIFTPs size was the only significantly different parameter. Preoperatively, NIFTP nodules mostly showed low-risk US characteristics, indeterminate cytology and a RAS-like molecular profile. Conclusion: NIFTPs often coexist with collateral thyroid tumours. However, no clinical-pathological differences can be observed between solitary and "multifocal" NIFTPs. Despite the well-established clinical indolence of NIFTP, a careful monitoring of the contralateral lobe should not be excluded.
\end{abstract}

Keywords: thyroid tumours; NIFTP; molecular pathology; FNA; cytology

\section{Introduction}

Since 2016, a new histological entity was introduced in the classification of thyroid tumours: non-invasive follicular thyroid neoplasms with papillary-like nuclear features (NIFTPs) made their first appearance in thyroid pathology [1]. NIFTPs were previously classified as encapsulated follicular variant papillary thyroid carcinoma (FVPTC). FVPTCs represent $30 \%$ of papillary thyroid carcinoma (PTC) [2]; they show the nuclear characteristics typical of PTC, but an almost exclusive follicular growth pattern [3]. FVPTCs can be divided in two main subtypes: infiltrative and encapsulated (with or without invasion of tumour capsule) [4]. Infiltrative FVPTCs can show recurrence, have a metastatic potential, and a BRAF mutation frequency of about $25 \%$ [5]. In contrast, encapsulated FVPTCs 
show lower risk of recurrence and lymph node metastases, with a high prevalence of $R A S$ mutations and lack of $B R A F^{V 600 E}$ mutations [6,7]. It has been demonstrated that these tumours, when no capsular nor vascular invasion is present, have an excellent prognosis after complete resection, even when treated only with lobectomy [8,9]. Therefore, based on their low-risk molecular profile and indolent biological behaviour, they should be distinguished from infiltrative FVPTCs [5,10]. To reduce clinical overtreatment and psychological consequences associated with a diagnosis of "cancer", non-invasive encapsulated FVPTCs have been reclassified as NIFTPs [1], with the goal to denote a group of follicular neoplasm with an indolent behaviour [11]. The diagnosis of NIFTP is only possible after surgical excision of the nodule, because the tumour capsule must be entirely inspected to exclude invasion foci. Moreover, a preoperative NIFTP diagnosis is extremely difficult, as they do not show peculiar ultrasound (US) nor cyto-morphological features [12]. On fine-needle aspiration (FNA), they are mostly classified as indeterminate nodules [13].

From the molecular point of view, as reported by TCGA, PTCs can be divided into $B R A F^{V 600 E}$-like and $R A S$-like [14] tumours, and NIFTPs are unequivocally RAS-like lesions [15]. NIFTPs harbour RAS mutations in 40-70\% of cases, while BRAF ${ }^{V 600 E}$ mutation should not be detected in NIFTPs [16]. $B R A F^{\mathrm{K} 601 \mathrm{E}}$ can be present, and has been detected in $2-11.5 \%$ of cases. Furthermore, NIFTPs harbour gene fusions in PPARG and THADA genes, typically detected in RAS-like tumours, with a prevalence of $22 \%$ and $40 \%$, respectively [16]. Therefore, the molecular profile of NIFTP does not allow a definitive preoperative identification.

In the present study, a large mono-institutional series of NIFTP has been retrospectively evaluated. The aim was to investigate clinico-pathological characteristics of NIFTP with a particular focus on the multifocal scenario, which represent a controversial issue. Potential differences between NIFTPs as solitary tumours and in multifocal setting have been also investigated, taking into account US, cytology, and molecular NIFTP features.

\section{Materials and Methods}

A retrospective search of non-invasive follicular thyroid neoplasm with papillary-like nuclear features (NIFTP) was performed in the database of the Surgical Pathology Section of the University Hospital of Pisa from January 2016 to December 2020. A search of the term "NIFTP" was used for the selection of cases. The entire series of haematoxylin-eosin slides of all cases were reviewed by three pathologists (F.B., A.P., and L.T.) with experience in thyroid pathology, according to the current World Health Organization (WHO) criteria [4]. The following clinico-pathological features of NIFTP were recorded: tumour size, nuclear score, percentage of solid areas, and presence of multifocal disease, i.e., NIFTP coexisting with one or more NIFTP / carcinoma. In this last case, the size and histotype of collateral carcinoma were specified; moreover, the clinically most relevant nodule (index nodule) was identified based on clinical information reported on the pathological report.

For a subgroup of patients, pre-surgical ultrasound (US) evaluation, cytological diagnosis, and molecular analysis were available.

Neck US examination was performed by Real-time instrument (Technos, Esaote Biomedica, Genova, Italy) with a 7.5-MHz linear transducer [17]. Characteristics of nodules in terms of nodule composition, borders, echogenicity, shape, and presence of microcalcifications were recorded. Nodules were scored according to the EU-TIRADS system [18].

Cytological diagnosis was performed following both the Bethesda System for Reporting Thyroid Cytopathology (TBSRTC) [19] and the Italian Consensus for Classification and Reporting of Thyroid Cytology (ICCRTC) [20].

Molecular analysis was performed on formalin-fixed, paraffin-embedded tissue of patients whose cytological evaluation was performed in our institution, and biological material was available DNA was purified by using the Qiamp DNA Mini kit (Qiagen, Hilden, Germany). One paraffin block was selected for each case, and 2 to $610 \mu \mathrm{m}-$ tick sections were obtained. After standard deparaffinization and rehydration of sections, tumour areas were collected by manual macrodissection and placed in a tube containing the 
lysis buffer and proteinase-K. All subsequent procedures for nucleic acids purification were performed following the protocol provided by the manufacturer. DNA was analysed for $R A S$ family mutations exon 3 (NRAS, HRAS, and KRAS) and BRAF exon 15 by using highresolution melt analysis (Type-it HRM PCR Kit, Qiagen) followed by direct sequencing.

Continuous variables are presented as median and interquartile range (IQR) and were analysed by the Mann-Whitney $U$ test. The association between categorical variables were assessed by the Chi-square test or the Fisher exact test whenever appropriate. The analyses were carried out in R environment (https: / / www.r-project.org/, version 4.1.2, last accessed on 25 November 2021).

\section{Results}

A total of 451 patients with NIFTP were retrieved. There were $321(71.2 \%)$ female and $130(28.8 \%)$ male patients. The median age was 50 years (IQR 40-59). The clinicopathological characteristics of NIFTPs are summarized in Table 1. The median size of the lesion was $1.7 \mathrm{~cm}$ (IQR 0.9-3.0); 148 (32.8\%) patients had microNIFTP $(\leq 1 \mathrm{~cm})$. The majority of lesions $(85.4 \%$ ) had a nuclear score of 2 and $14.6 \%$ of 3 . There were no solid areas in $286(63.4 \%)$ lesions, while in 165 (36.6\%) lesions, solid areas were present with a percentage lower than 30\% (Figure 1). In 186 cases (41.2\%), NIFTP was in the context of normal parenchyma (solitary nodule). In the remaining cases, it was found in the context of multinodular thyroid parenchyma $(58.8 \%)$. NIFTP size was significantly larger in solitary cases ( $p$-value $<0.0001)$.

Table 1. Description of 451 NIFTP cases.

\begin{tabular}{cc}
\hline NIFTP Clinico-Pathological Characteristics & N (\%) \\
Gender & \\
Female & $321(71.2)$ \\
Male & $130(28.8)$ \\
\hline Age, median (IQR) & $50(40-59)$ \\
\hline Size $[\mathrm{cm}]$, median (IQR) & $1.7(0.9-3.0)$ \\
\hline microNIFTP $(\leq 1 \mathrm{~cm})$ & $148(32.8)$ \\
\hline Nuclear Score & $385(85.4)$ \\
2 & $66(14.6)$ \\
\hline Solid areas & \\
Absent & $286(63.4)$ \\
Present $(<30 \%)$ & $165(36.6)$ \\
\hline Normal & $186(41.2)$ \\
Multinodular & $265(58.8)$ \\
\hline
\end{tabular}

Abbreviations: NIFTP, non-invasive follicular thyroid neoplasm with papillary-like nuclear features; IQR, interquartile range.

A total of 197 NIFTPs (43.7\%) presented with one or more collateral NIFTP/malignant thyroid tumours, as shown in Table 2. NIFTP that coexisted with collateral malignant tumours were significantly smaller ( $p$-value $<0.001)$, and total thyroidectomy rate was significantly higher $(p$-value $<0.0001)$. Among patients with collateral malignant lesions submitted to hemithyroidectomy, four needed repeated surgery for completion thyroidectomy. In the contralateral lobe, histological examination showed a microPTC in one patient.

The histotype of malignant tumours coexisting with NIFTP is reported in Table 3. In multifocal disease setting, there were predominantly papillary thyroid cancers (PTC), mainly microPTCs. Detailed distribution of coexisting NIFTPs/cancers is shown in Figure 2. 

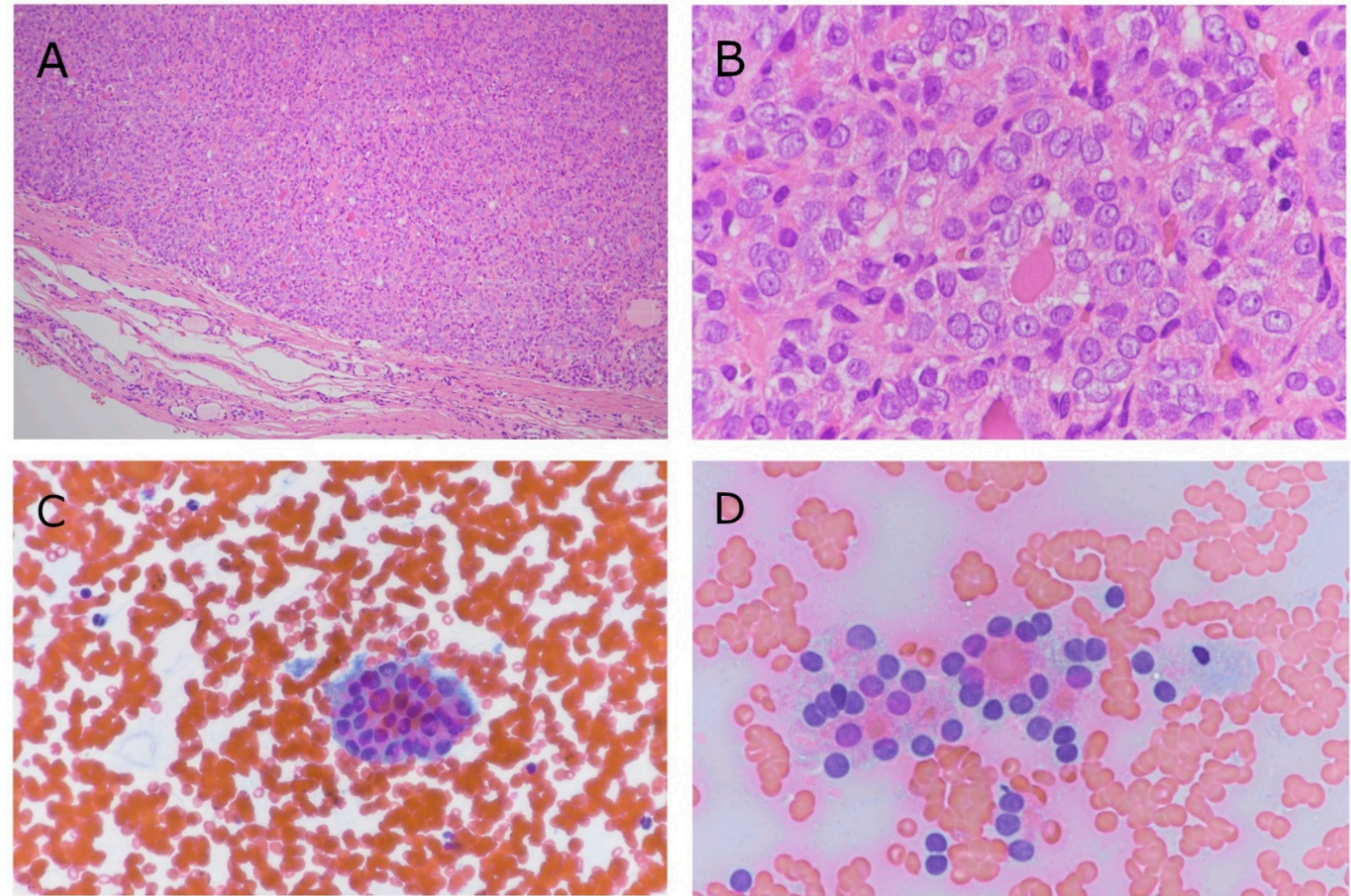

Figure 1. Histopathological and cytological images of NIFTPs. (A) Low magnification (original magnification: $10 \times$ ). The tumour appears completely encapsulated without signs of vascular and/or capsular invasion. (B) Higher magnification $(60 \times)$ of neoplastic cells. Papillary-like nuclear features are evident at this magnification. (C) Cytological smear of the same case diagnosed as indeterminate nodule $(60 \times)$. The picture shows a microfollicular structure with mild/moderate nuclear atypia. (D) Another NIFTP case with indeterminate cytology. Two microfollicles are reported at high magnification $(60 \times)$.

Table 2. Characteristics of NIFTP with and without collateral malignant lesions.

\begin{tabular}{|c|c|c|c|}
\hline \multirow{2}{*}{ Variation } & \multicolumn{2}{|c|}{$\begin{array}{l}\text { NIFTP } \\
N=451\end{array}$} & \multirow[b]{2}{*}{$p$-Value } \\
\hline & $\begin{array}{l}\text { Absence of Collateral Malignant Lesions } \\
\qquad N=254(56.3 \%)\end{array}$ & $\begin{array}{l}\text { Presence of Collateral Malignant Lesions } \\
\qquad N=197(43.7 \%)\end{array}$ & \\
\hline $\begin{array}{l}\text { Gender } \\
\text { Female } \\
\text { Male }\end{array}$ & $\begin{array}{l}179(70.5) \\
75(29.5)\end{array}$ & $\begin{array}{l}142(72.1) \\
55(27.9)\end{array}$ & 0.79 \\
\hline Age, median (IQR) & $50(39-59)$ & $51(43-59)$ & 0.44 \\
\hline Size $[\mathrm{cm}]$, median (IQR) & $2(1.0-3.3)$ & $1.4(0.8-2.5)$ & $<0.0001$ \\
\hline $\begin{array}{c}\text { Nuclear score } \\
2 \\
3\end{array}$ & $\begin{array}{l}218(85.8) \\
36(14.2)\end{array}$ & $\begin{array}{l}167(84.8) \\
30(15.2)\end{array}$ & 0.86 \\
\hline $\begin{array}{c}\text { Solid areas } \\
\text { Absent } \\
\text { Present }(<30 \%)\end{array}$ & $\begin{array}{l}158(62.2) \\
96(37.8)\end{array}$ & $\begin{array}{l}128(65.0) \\
69(35.0)\end{array}$ & 0.61 \\
\hline $\begin{array}{c}\text { Localization of collateral malignant lesions } \\
\text { Ipsilateral } \\
\text { Contralateral }\end{array}$ & / & $\begin{array}{l}109(55.3) \\
88(44.7)\end{array}$ & \\
\hline $\begin{array}{l}\text { Type of surgery } \\
\text { Total thyroidectomy } \\
\text { Lobectomy }\end{array}$ & $\begin{array}{l}181(71.3) \\
73(28.7)\end{array}$ & $\begin{array}{l}174(88.3) \\
23(11.7)\end{array}$ & $<0.0001$ \\
\hline
\end{tabular}

Abbreviations: NIFTP, non-invasive follicular thyroid neoplasm with papillary-like features; IQR, interquartile range. 
Table 3. Histotype of the malignant lesions found in coexistence with NIFTPs in 197 patients. MicroPTC have not been included in this table.

\begin{tabular}{cc}
\hline Histological Type & $\boldsymbol{N} \mathbf{( \% )}$ \\
\hline PTC & $80(93.0)$ \\
FVPTC & $32(40.0)$ \\
CVPTC & $25(31.3)$ \\
SVPTC & $14(17.5)$ \\
TCVPTC & $6(7.5)$ \\
OXPTC & $2(2.5)$ \\
MFPTC & $1(1.2)$ \\
\hline FTC & $5(5.8)$ \\
\hline MTC & $1(1.2)$
\end{tabular}

Abbreviations: PTC, papillary thyroid carcinoma, FVPTC, follicular-variant of papillary thyroid carcinoma, CVPTC, classical-variant of papillary thyroid carcinoma, SVPTC, solid-variant of papillary thyroid carcinoma, TCVPTC, tall-cell variant papillary thyroid carcinoma, OXVPTC, oxyphilic-variant of papillary thyroid carcinoma, MFPTC, macro follicular papillary thyroid carcinoma, FTC, follicular thyroid carcinoma, and MTC, medullary thyroid carcinoma.

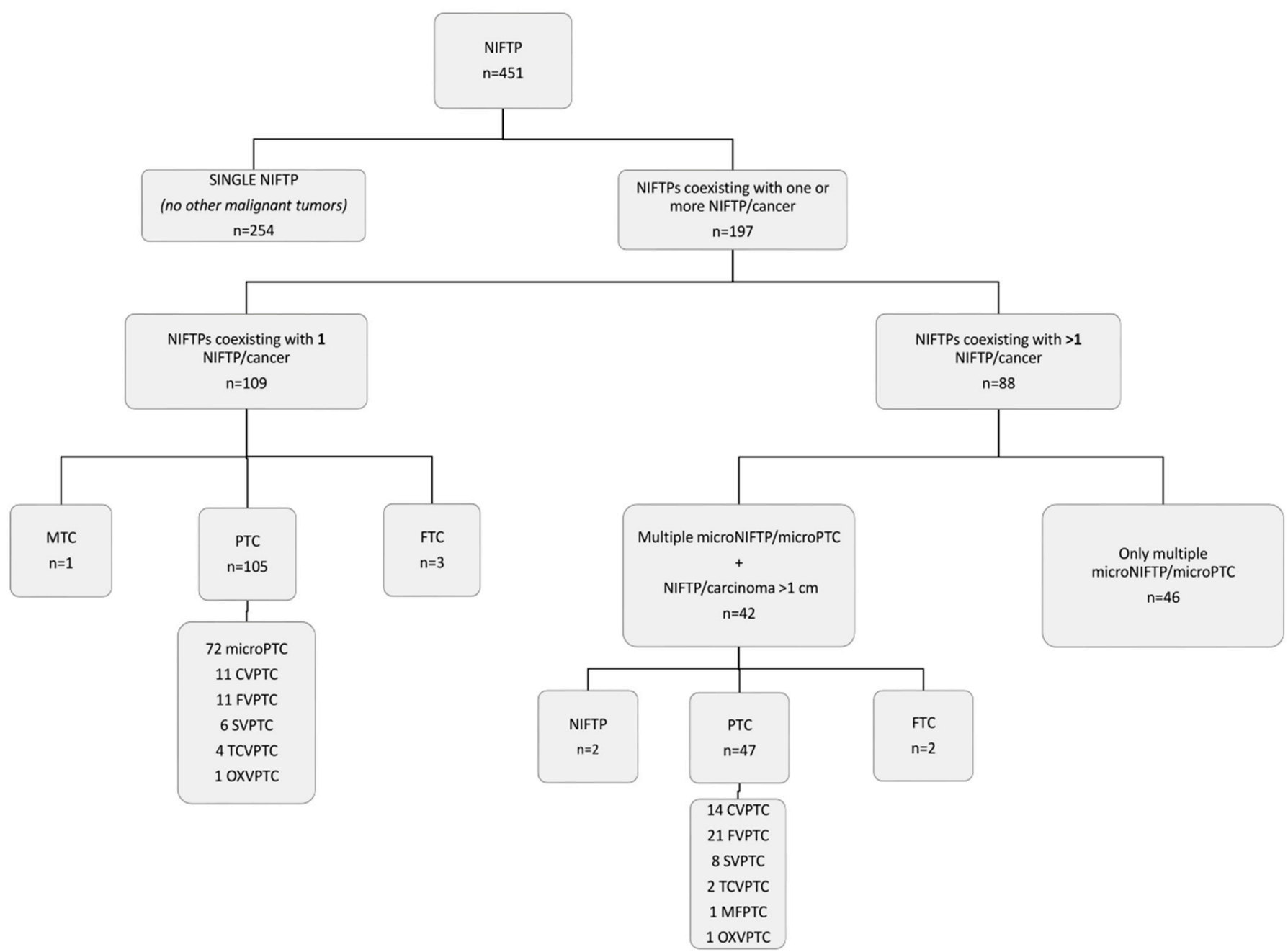

Figure 2. Detailed distribution of the 451 NIFTPs with or without other coexisting thyroid lesions. Abbreviations: NIFTP, non-invasive follicular thyroid neoplasm with papillary-like features, MTC, medullary thyroid carcinoma, PTC, papillary thyroid carcinoma, FTC, follicular thyroid carcinoma, CVPTC, classical-variant of papillary thyroid carcinoma, FVPTC, follicular-variant of papillary thyroid carcinoma, SVPTC, solid-variant of papillary thyroid carcinoma, TCVPTC, tall-cell variant papillary thyroid carcinoma, and OXVPTC, oxyphilic-variant of papillary thyroid carcinoma. 
NIFTP was the index lesion in 117 out of 197 multiple cases (59.4\%); in 61 cases (31.0\%) another malignant lesion was the index nodule; in 19 cases $(9.6 \%)$ the index nodule was a benign thyroid nodule. When NIFTP was not the index lesion, its size was $\leq 1 \mathrm{~cm}$ in 50 out of 80 cases $(62.5 \%)$. When NIFTP was the index lesion, the collateral malignant tumour was $\leq 1 \mathrm{~cm}$ in 102 out of 117 cases $(87.2 \%)$. In 15 cases $(12.8 \%)$, the collateral malignant carcinoma was greater than $1 \mathrm{~cm}$ in diameter. NIFTP considered as index nodules were significantly larger ( $p$-value $<0.0001)$.

For a subset of NIFTP cases, information on US features, presurgical cytological diagnosis, and molecular results was available (Table 4). US characteristics were low-risk in the majority of nodules (solid composition in 95.3\%; well-defined borders in $96.5 \%$; absence of microcalcifications in $97.7 \%$; isoechoic pattern in $62.8 \%$; wider-than-tall in $94.2 \%$; and EU-TIRADS 3 category in $96.5 \%$ of cases). As regards multifocality, 40 out of 86 nodules (46.5\%) on histology were single NIFTPs, while 46 out of 86 nodules (53.5\%) were NIFTPs coexisting with collateral malignant tumours. US features were not significantly different according to multifocality.

Table 4. Subset of NIFTP cases with available cytological diagnosis, ultrasound data, and molecular analysis.

\begin{tabular}{|c|c|c|c|}
\hline \multicolumn{3}{|c|}{$\begin{array}{l}\text { Presurgical US Characteristics of NIFTPs } \\
\qquad n=86\end{array}$} & N (\%) \\
\hline \multicolumn{3}{|c|}{ Nodule composition } & \\
\hline \multicolumn{3}{|c|}{ Solid } & $82(95.3)$ \\
\hline \multicolumn{3}{|c|}{ Mixed } & $3(3.5)$ \\
\hline \multicolumn{3}{|c|}{ Spongiform } & $1(1.2)$ \\
\hline \multicolumn{4}{|c|}{ Borders } \\
\hline \multicolumn{3}{|c|}{ Well-defined } & $83(96.5)$ \\
\hline \multicolumn{3}{|c|}{ Lobulated or irregular } & $3(3.5)$ \\
\hline \multicolumn{4}{|c|}{ Microcalcifications } \\
\hline \multicolumn{3}{|c|}{ Yes } & $2(2.3)$ \\
\hline \multicolumn{3}{|c|}{ No } & $84(97.7)$ \\
\hline \multicolumn{4}{|c|}{ Echogenicity } \\
\hline \multicolumn{3}{|c|}{ Isoechoic } & $54(62.8)$ \\
\hline \multicolumn{3}{|c|}{ Hyperechoic } & $3(3.5)$ \\
\hline \multicolumn{3}{|c|}{ Hypoechoic } & $28(32.5)$ \\
\hline \multicolumn{3}{|c|}{ Anechoic } & $1(1.2)$ \\
\hline \multicolumn{4}{|c|}{ Shape } \\
\hline \multicolumn{3}{|c|}{ Wider-than-tall } & $81(94.2)$ \\
\hline \multicolumn{3}{|c|}{ Taller-than-wide } & $3(3.5)$ \\
\hline \multicolumn{3}{|c|}{ Missing data } & $2(2.3)$ \\
\hline \multicolumn{4}{|c|}{ EU-TIRADS } \\
\hline \multicolumn{3}{|c|}{2} & $3(3.5)$ \\
\hline \multicolumn{3}{|c|}{3} & $83(96.5)$ \\
\hline $\begin{array}{l}\text { Cytology } \\
n=184\end{array}$ & \multicolumn{2}{|l|}{$\mathrm{N}(\%)$} & $\mathrm{N}(\%)$ \\
\hline \multicolumn{3}{|l|}{ TBSRTC } & \\
\hline I & $10(5.4)$ & TIR1 & $10(5.4)$ \\
\hline II & $34(18.5)$ & TIR2 & $34(18.5)$ \\
\hline III & $91(49.5)$ & TIR3A & $92(50.0)$ \\
\hline IV & $42(22.8)$ & TIR3B & $41(22.3)$ \\
\hline $\mathrm{V}$ & $6(3.3)$ & TIR4 & $6(3.3)$ \\
\hline
\end{tabular}


Table 4. Cont.

\begin{tabular}{ccc}
\hline \multicolumn{1}{c}{$\begin{array}{c}\text { Presurgical US Characteristics of NIFTPs } \\
n=86\end{array}$} & N (\%) \\
\hline VI $1(0.5)$ & TIR5 & $10.5)$ \\
\hline \multicolumn{1}{c}{$\begin{array}{c}\text { Molecular Analysis } \\
n=137\end{array}$} & N Mutated (\%) \\
\hline Ras family genes mutations \\
NRAS \\
HRAS \\
KRAS \\
non-V600E BRAF mutations \\
Total \\
\hline
\end{tabular}

Abbreviations: TBSRTC, the Bethesda system for reporting thyroid cytopathology, ICCRTC, Italian consensus for classification and reporting of thyroid cytology, US, ultrasound; and NIFTP, non-invasive follicular thyroid neoplasm with papillary-like features.

The most represented cytological category was the Bethesda III (TIR3A), in 91 out of 184 nodules $(49.5 \%)$.

Material to perform molecular analysis was available in 137 cases. As shown in Table 4, 62 NIFTP out of 137 (45.3\%) were mutated. The majority of NIFTP harboured RAS mutations (40.1\%), while only $5.1 \%$ of NIFTP harboured non-V600E BRAF mutations: four were mutated in codon 601 (p.K601E), one had a deletion (p.T599del), one had an insertion (p.A598_T599insV) and one had a delins (p.V600_S605delVKSRWSinsD). NIFTP mutational status showed no statistical associations with cytological categories nor US features; moreover, there were no associations between the presence of mutations and NIFTP histological features, including solitary/multifocal tumours.

\section{Discussion}

Non-invasive follicular thyroid neoplasms with papillary-like features (NIFTP) have been in the classification of thyroid cancers since 2016 [1]. NIFTP is a follicular cell-derived non-invasive neoplasm with a follicular growth pattern and nuclear features of papillary thyroid carcinoma (PTC) that has an extremely low malignant potential [4]. According to the latest guidelines of the World Health Organization, NIFTP is a solitary, well-demarcated nodule, typically with a thin to moderately thick capsule. The tumours are usually $2-4 \mathrm{~cm}$ in size but can be much larger.

Over the last 5 years, several clinico-pathological aspects related to NIFTP have been investigated.

$\mathrm{Xu}$ and colleagues tried to investigate whether also subcentimeter, non-invasive encapsulated follicular variant (NI-EFV) PTC could be renamed as NIFTP. They collected 52 patients with unifocal microPTC NI-EFV, with a control group of invasive microPTC $(n=52)$. They did not observe recurrence in the group of microPTC NI-EFV, while in the control group there were cases of nodal metastasis and recurrence. Subcentimeter NI-EFV PTC were characterized by extremely indolent clinical course, and should be considered as NIFTP [21]. The same group evaluated a series of non-invasive encapsulated FVPTC with oncocytic features, and confirmed their indolent clinical behaviour [22]. Recently, the importance of the complete tumour encapsulation has been also highlighted in classical PTCs [23].

The concept of solitary NIFTP, intended as a single thyroid nodule in the context of normal parenchyma, has been also questioned. Some authors tried to address the issue of multifocal and collateral disease in the context of NIFTP. Canberk and colleagues collected a series 74 NIFTP (including lesions $<1 \mathrm{~cm}$ in size), of which 61 were solitary $(82.4 \%)$ and 13 were multifocal (17.6\%), specifically, 11 were PTC and 2 were NIFTPs. They demonstrated that multifocal lesions tend to be associated with an index lesion with smaller size, and their findings reinforce previous suggestions that multifocal disease is part of the spectrum 
of NIFTP neoplasm [24,25]. Canini and colleagues collected 68 NIFTP in a 9 year-long period, including nodules smaller than $1 \mathrm{~cm}$. In their study, 41 NIFTP $(60.1 \%)$ were in a context of multinodular parenchyma: a significant proportion of these NIFTPs were incidental $(29 \%)$. In 10 out of 68 cases $(14.7 \%)$, NIFTPs were in coexistence with a thyroid carcinoma. These authors suggest that close monitoring of the contralateral lobe in patients with NIFTP not submitted to total thyroidectomy should be performed [26]. Song and colleagues collected 87 NIFTP cases from 82 patients. In 38 patients (46.3\%), 75 malignant tumours were identified, mostly microPTCs [27]. Seo and colleagues collected 238 cases of NIFTPs, of which $64(26.7 \%)$ coexisted with other malignant thyroid tumours [28]. On the other hand, Turan and Ozkara retrospectively evaluated 481 FVPTCs, of which 84 (3.9\%) matched a diagnosis of NIFTP. Most of them were solitary NIFTPs, while 15 were multifocal NIFTPs $(17.9 \%)$; cases in which NIFTP coexisted with other thyroid malignancies were excluded [29].

Herein, we have collected the largest retrospective and monocentric series of patients with diagnosis of NIFTP $(n=451)$, which were included independently of the presence of coexisting thyroid tumours. In our study, 197 out of 451 NIFTP (43.7\%) were in coexistence with one or more collateral NIFTP or malignant lesions. The size of multiple NIFTPs size was significantly smaller compared to that of solitary ones. Total thyroidectomy rate was significantly higher in NIFTPs that coexisted with one or more collateral thyroid lesions, likely because they presented more frequently with multinodular parenchyma.

Interestingly, among 197 cases of NIFTP coexisting with other malignant lesions, collateral lesions were present both in the same lobe (55.3\%) and in the contralateral lobe (44.7\%). As shown in Figure 2, in 109 cases, NIFTP coexisted with only one other NIFTP or carcinoma; in 88 cases, NIFTP coexisted with multiple NIFTPs or carcinomas. The coexistence of multiple NIFTPs, as well as NIFTP with one collateral thyroid malignancy, has been already described with a frequency ranging from 14.7 to $46.3 \%$ [24-28]. However, the fact that in 88 cases of our series one NIFTP presented with multiple thyroid carcinomas in the same patient represents an unexpected finding, which further complicates the controversy of how a NIFTP should be named and managed in the multifocal setting. Another interesting observation was that, in 46 out of 88 patients, NIFTP coexisted with only multiple microNIFTP and/or microPTC. MicroPTCs are quite common in the general population, and often represent an incidental finding [30]. The American Thyroid Association (ATA) included unifocal or multifocal microPTC as low-risk tumours, unless extrathyroidal extension is present [31]. However, in recent years, the optimal management of microPTC has been subjected to discussion, and further risk-stratification of microPTC seems necessary [30,32].

Moreover, in a considerable number of patients (42 out of $88,9.3 \%$ of the entire cohort), NIFTP was in the presence of carcinomas greater than $1 \mathrm{~cm}$, the majority being PTCs. These tumours, clearly guided clinical patients' management independently of the presence of NIFTP, which have different therapeutic indications and a likely-benign behaviour. In this context, it should be highlighted that in 117 out of 197 "multifocal" cases, NIFTP was considered the index nodule (59.4\%); in 102 cases, the collateral lesion was a microNIFTP/microPTC, while, in the remaining 15 cases $(12.8 \%)$, the collateral carcinoma was greater than $1 \mathrm{~cm}$. Therefore, in this group of cases, the nodule corresponding to the NIFTP would have guided the management of patients.

Furthermore, in our series, NIFTP had a very often a preoperative indeterminate cytology (Bethesda III, TIR3A). These data are in line with previous studies, that underline the morphological overlap between NIFTP and other follicular neoplasms including papillary thyroid carcinoma [33]. Therefore, even performing a careful examination, NIFTPs cannot be further characterized on cytology. Similarly, the molecular profile of NIFTPs overlaps to that of follicular thyroid lesions, i.e., mostly RAS mutations.

Our study presents some limitations. One of these is the retrospective nature of the study. Moreover, our findings including US, cytological, and molecular data were limited to a subgroup of the NIFTP cohort. Finally, the mutational screening of nodules included 
only part of the spectrum of RAS-like mutations, while alterations in genes such as THADA and PPARG were not tested.

\section{Conclusions}

To sum up, NIFTP can be found as a solitary thyroid nodule or in coexistence with other thyroid nodules, either benign or malignant. In our series, no significant differences were found between single and multiple NIFTPs in terms of clinico-pathological characteristics, with the exception of NIFTP size.

Considering the high rate of coexisting carcinomas, and despite the clinical indolence of NIFTP, a careful monitoring of the contralateral lobe should not be excluded.

Author Contributions: Conceptualization and study design, P.V. and F.B.; methodology, P.V., A.P. and E.M.; investigation, data interpretation, P.V., A.P., E.M., A.M.P., L.T., C.U., A.B., A.M. and T.R.; data analysis, statistics, P.V. and A.M.P.; original draft preparation, P.V. and A.P.; writing, review and editing, all authors; and supervision, F.B., G.M., R.E. and F.S. All authors have read and agreed to the published version of the manuscript.

Funding: Reagents and consumables were obtained with funds from the University of Pisa.

Institutional Review Board Statement: The study was conducted according to the guidelines of the Declaration of Helsinki, and was approved by the Institutional Ethical Committee (protocol number 9989/2019).

Informed Consent Statement: The study was conducted on anonymous archive samples; thus, patient consent was waived.

Data Availability Statement: All data generated or analysed during this study are included in this manuscript.

Conflicts of Interest: The authors declare no conflict of interest.

\section{References}

1. Nikiforov, Y.E.; Seethala, R.R.; Tallini, G.; Baloch, Z.W.; Basolo, F.; Thompson, L.D.R.; Barletta, J.A.; Wenig, B.M.; Al Ghuzlan, A.; Kakudo, K.; et al. Nomenclature Revision for Encapsulated Follicular Variant of Papillary Thyroid Carcinoma: A Paradigm Shift to Reduce Overtreatment of Indolent Tumors. JAMA Oncol. 2016, 2, 1023. [CrossRef] [PubMed]

2. Baloch, Z.W.; Shafique, K.; Flanagan, M.; LiVolsi, V.A. Encapsulated Classic and Follicular Variants of Papillary Thyroid Carcinoma: Comparative Clinicopathologic Study. Endocr. Pract. 2010, 16, 952-959. [CrossRef] [PubMed]

3. Kim, M.J.; Won, J.-K.; Jung, K.C.; Kim, J.; Cho, S.W.; Park, D.J.; Park, Y.J. Clinical Characteristics of Subtypes of Follicular Variant Papillary Thyroid Carcinoma. Thyroid 2018, 28, 311-318. [CrossRef] [PubMed]

4. International Agency for Research on Cancer; Lloyd, R.V.; Osamura, R.Y.; Klöppel, G.; Rosai, J. WHO Classification of Tumors of Endocrine Organs, 4th ed.; IARC Press: Lyon, French, 2017.

5. Howitt, B.E.; Jia, Y.; Sholl, L.M.; Barletta, J.A. Molecular Alterations in Partially-Encapsulated or Well-Circumscribed Follicular Variant of Papillary Thyroid Carcinoma. Thyroid 2013, 23, 1256-1262. [CrossRef] [PubMed]

6. Welch, H.G.; Doherty, G.M. Saving Thyroids-Overtreatment of Small Papillary Cancers. N. Engl. J. Med. 2018, 379, 310-312. [CrossRef] [PubMed]

7. Zhu, Z.; Gandhi, M.; Nikiforova, M.N.; Fischer, A.H.; Nikiforov, Y.E. Molecular Profile and Clinical-Pathologic Features of the Follicular Variant of Papillary Thyroid Carcinoma: An Unusually High Prevalence of Ras Mutations. Am. J. Clin. Pathol. 2003, 120, 71-77. [CrossRef] [PubMed]

8. Ganly, I.; Wang, L.; Tuttle, R.M.; Katabi, N.; Ceballos, G.A.; Harach, H.R.; Ghossein, R. Invasion Rather than Nuclear Features Correlates with Outcome in Encapsulated Follicular Tumors: Further Evidence for the Reclassification of the Encapsulated Papillary Thyroid Carcinoma Follicular Variant. Human Pathol. 2015, 46, 657-664. [CrossRef]

9. Rosario, P.W.; Penna, G.C.; Calsolari, M.R. Noninvasive Encapsulated Follicular Variant of Papillary Thyroid Carcinoma: Is Lobectomy Sufficient for Tumours $\geq 1 \mathrm{~cm}$ ? Clin. Endocrinol. 2014, 81, 630-632. [CrossRef]

10. Rivera, M.; Ricarte-Filho, J.; Knauf, J.; Shaha, A.; Tuttle, M.; Fagin, J.A.; Ghossein, R.A. Molecular Genotyping of Papillary Thyroid Carcinoma Follicular Variant According to Its Histological Subtypes (Encapsulated vs. Infiltrative) Reveals Distinct BRAF and RAS Mutation Patterns. Mod. Pathol. 2010, 23, 1191-1200. [CrossRef] [PubMed]

11. Dhanushika, T.; Priyani, A.A.H.; Ranaweera, M.E.M.; Ranaweera, G.G.; de Silva, M.V.C.; Dassanayake, R.S. A Closer Look at NIFTP. Hormones 2020, 19, 285-290. [CrossRef] 
12. Boursier, L.; Clerc Urmes, I.; Garon, J.; Klein, M.; Demarquet, L. Ultrasound and Cytological Characteristics of Non-Invasive Follicular Thyroid Neoplasm with Papillary-like Nuclear Features Compared to Papillary Carcinomas. Ann. Endocrinol. 2020, 81, 28-33. [CrossRef] [PubMed]

13. Maletta, F.; Falco, E.C.; Gambella, A.; Metovic, J.; Papotti, M. Noninvasive Follicular Thyroid Neoplasm with Papillary-Like Nuclear Features: From Echography to Genetic Profile. Tohoku J. Exp. Med. 2020, 252, 209-218. [CrossRef] [PubMed]

14. Agrawal, N.; Akbani, R.; Aksoy, B.A.; Ally, A.; Arachchi, H.; Asa, S.L.; Auman, J.T.; Balasundaram, M.; Balu, S.; Baylin, S.B.; et al. Integrated Genomic Characterization of Papillary Thyroid Carcinoma. Cell 2014, 159, 676-690. [CrossRef] [PubMed]

15. Basolo, F.; Macerola, E.; Ugolini, C.; Poller, D.N.; Baloch, Z. The Molecular Landscape of Noninvasive Follicular Thyroid Neoplasm With Papillary-like Nuclear Features (NIFTP): A Literature Review. Adv. Anat. Pathol. 2017, 24, 252-258. [CrossRef]

16. Macerola, E.; Proietti, A.; Basolo, F. Noninvasive Follicular Neoplasm with Papillary-like Nuclear Features (NIFTP): A New Entity. Gland Surg. 2020, 9, S47-S53. [CrossRef]

17. Liu, R.; Gao, L.; Xia, Y.; Li, X.; Liao, Q.; Jiang, Y.; Zhang, Q.; Chen, C.; Zhang, L.; Liang, Z.; et al. Three Ultrasound Phenotypes of Non-Invasive Follicular Thyroid Neoplasm with Papillary-like Nuclear Features Proposed for Imaging-Pathology Analysis: Single Center Experience. Gland Surg. 2021, 10, 307-318. [CrossRef] [PubMed]

18. Russ, G.; Bonnema, S.J.; Erdogan, M.F.; Durante, C.; Ngu, R.; Leenhardt, L. European Thyroid Association Guidelines for Ultrasound Malignancy Risk Stratification of Thyroid Nodules in Adults: The EU-TIRADS. Eur. Thyroid J. 2017, 6, $225-237$. [CrossRef] [PubMed]

19. Cibas, E.S.; Ali, S.Z. The 2017 Bethesda System for Reporting Thyroid Cytopathology. Thyroid 2017, 27, 1341-1346. [CrossRef] [PubMed]

20. Nardi, F.; Basolo, F.; Crescenzi, A.; Fadda, G.; Frasoldati, A.; Orlandi, F.; Palombini, L.; Papini, E.; Zini, M.; Pontecorvi, A.; et al Italian Consensus for the Classification and Reporting of Thyroid Cytology. J. Endocrinol. Investig. 2014, 37, 593-599. [CrossRef]

21. Xu, B.; Farhat, N.; Barletta, J.A.; Hung, Y.P.; de Biase, D.; Casadei, G.P.; Onenerk, A.M.; Tuttle, R.M.; Roman, B.R.; Katabi, N.; et al. Should Subcentimeter Non-Invasive Encapsulated, Follicular Variant of Papillary Thyroid Carcinoma Be Included in the Noninvasive Follicular Thyroid Neoplasm with Papillary-like Nuclear Features Category? Endocrine 2018, 59, 143-150. [CrossRef] [PubMed]

22. Xu, B.; Reznik, E.; Tuttle, R.M.; Knauf, J.; Fagin, J.A.; Katabi, N.; Dogan, S.; Aleynick, N.; Seshan, V.; Middha, S.; et al. Outcome and Molecular Characteristics of Non-Invasive Encapsulated Follicular Variant of Papillary Thyroid Carcinoma with Oncocytic Features. Endocrine 2019, 64, 97-108. [CrossRef]

23. Giani, C.; Torregrossa, L.; Ramone, T.; Romei, C.; Matrone, A.; Molinaro, E.; Agate, L.; Materazzi, G.; Piaggi, P.; Ugolini, C.; et al. Whole Tumor Capsule Is Prognostic of Very Good Outcome in the Classical Variant of Papillary Thyroid Cancer. J. Clin. Endocrinol. Metab. 2021, 106, e4072-e4083. [CrossRef] [PubMed]

24. Thompson, L.D. Ninety-Four Cases of Encapsulated Follicular Variant of Papillary Thyroid Carcinoma: A Name Change to Noninvasive Follicular Thyroid Neoplasm with Papillary-like Nuclear Features Would Help Prevent Overtreatment. Mod. Pathol. 2016, 29, 698-707. [CrossRef]

25. Canberk, S.; Montezuma, D.; Taştekin, E.; Grangeia, D.; Demirhas, M.P.; Akbas, M.; Tokat, F.; Ince, U.; Soares, P.; Schmitt, F. “The Other Side of the Coin": Understanding Noninvasive Follicular Tumor with Papillary-like Nuclear Features in Unifocal and Multifocal Settings. Human Pathol. 2019, 86, 136-142. [CrossRef] [PubMed]

26. Canini, V.; Leni, D.; Pincelli, A.I.; Scardilli, M.; Garancini, M.; Villa, C.; Di Bella, C.; Capitoli, G.; Cimini, R.; Leone, B.E.; et al. Clinical-Pathological Issues in Thyroid Pathology: Study on the Routine Application of NIFTP Diagnostic Criteria. Sci. Rep. 2019, 9, 13179. [CrossRef]

27. Song, S.J.; LiVolsi, V.A.; Montone, K.; Baloch, Z. Pre-Operative Features of Non-Invasive Follicular Thyroid Neoplasms with Papillary-like Nuclear Features: An Analysis of Their Cytological, Gene Expression Classifier and Sonographic Findings. Cytopathology 2017, 28, 488-494. [CrossRef] [PubMed]

28. Seo, J.Y.; Park, J.H.; Pyo, J.Y.; Cha, Y.J.; Jung, C.K.; Song, D.E.; Kwak, J.J.; Park, S.Y.; Na, H.Y.; Kim, J.-H.; et al. A Multi-Institutional Study of Prevalence and Clinicopathologic Features of Non-Invasive Follicular Thyroid Neoplasm with Papillary-like Nuclear Features (NIFTP) in Korea. J. Pathol. Transl. Med. 2019, 53, 378-385. [CrossRef] [PubMed]

29. Turan, G.; Özkara, S.K. Pathological Findings of the Retrospective Diagnosis of NIFTP (Non-Invasive Follicular Thyroid Neoplasm with Papillary-like Nuclear Features) in 84 Cases from Turkey and Systematic Review. Ann. Diagn. Pathol. 2021, $53,151764$. [CrossRef] [PubMed]

30. Provenzale, M.A.; Fiore, E.; Ugolini, C.; Torregrossa, L.; Morganti, R.; Molinaro, E.; Miccoli, P.; Basolo, F.; Vitti, P. 'Incidental' and 'Non-Incidental' Thyroid Papillary Microcarcinomas Are Two Different Entities. Eur. J. Endocrinol. 2016, 174, 813-820. [CrossRef]

31. Haugen, B.R.; Alexander, E.K.; Bible, K.C.; Doherty, G.M.; Mandel, S.J.; Nikiforov, Y.E.; Pacini, F.; Randolph, G.W.; Sawka, A.M.; Schlumberger, M.; et al. 2015 American Thyroid Association Management Guidelines for Adult Patients with Thyroid Nodules and Differentiated Thyroid Cancer: The American Thyroid Association Guidelines Task Force on Thyroid Nodules and Differentiated Thyroid Cancer. Thyroid 2016, 26, 1-133. [CrossRef] 
32. Ramundo, V.; Sponziello, M.; Falcone, R.; Verrienti, A.; Filetti, S.; Durante, C.; Grani, G. Low-risk Papillary Thyroid Microcarcinoma: Optimal Management toward a More Conservative Approach. J. Surg. Oncol. 2020, 121, 958-963. [CrossRef] [PubMed]

33. Pusztaszeri, M.; Bongiovanni, M. The Impact of Non-Invasive Follicular Thyroid Neoplasm with Papillary-like Nuclear Features (NIFTP) on the Diagnosis of Thyroid Nodules. Gland Surg. 2019, 8, S86-S97. [CrossRef] [PubMed] 